\title{
Shear Strength of Compacted Clays as Affected by Mineral Content and Wet-Dry Cycles
}

\author{
Frederick Nai Charkley $\mathbb{D}^{1,2}$ Kunyong Zhang $\mathbb{D}^{1,2}$ and Guoxiong Mei $\mathbb{D}^{1,2}$ \\ ${ }^{1}$ Key Laboratory of Ministry of Education for Geomechanics and Embankment Engineering, Nanjing 210098, China \\ ${ }^{2}$ Geotechnical Research Institute, Hohai University, Xikang Road 1\#, Nanjing, Jiangsu 210098, China \\ Correspondence should be addressed to Frederick Nai Charkley; fredioz@yahoo.com and Kunyong Zhang; ky_zhang@hhu.edu.cn
}

Received 17 April 2019; Revised 14 September 2019; Accepted 24 September 2019; Published 24 October 2019

Academic Editor: Fan Gu

Copyright @ 2019 Frederick Nai Charkley et al. This is an open access article distributed under the Creative Commons Attribution License, which permits unrestricted use, distribution, and reproduction in any medium, provided the original work is properly cited.

\begin{abstract}
The behaviors of high-plasticity clays depend largely on the clay mineral content. Recently, it has been observed that sudden slope failures of most clay slopes occur in regions pronounced with repeated rainfall and sunny climate. The reason for this is still unclear. Examining the effect of clay minerals and drastic weather changes on shear strength will be useful in predicting the performance of structures built in such soils and to take precautionary measures to improve the properties before failure. Therefore, a series of quick direct shearing tests were conducted on 11 artificial clay mixtures. The cohesion and frictional strength properties were determined and linked to the proportion of clay minerals and the number of wetting and drying cycles. The results show a significant reduction in shear strength after exposure to wetting and drying. Generally, montmorillonite-dominated mixtures were less susceptible to the changes in cohesion strength than kaolin-dominated mixtures, and the reduction in frictional strength was relatively insignificant.
\end{abstract}

\section{Introduction}

It is well acknowledged that the shear strength of compacted soils influences the stability of embankment slopes, the bearing capacity of foundations, and the performance of earth-retaining structures. Recently, it has been observed that the conventional method of using peak strength for the design of clay slopes overestimates the shear strength [1-3]. Therefore, the issue of determining the appropriate shear strength and the major influencing factors is a major concern for engineers during design and construction [4]. A typical example is the Carsington embankment which failed at a strength level considerably less than the peak strength [5].

It is now well established that the mechanical properties of clay depend largely on the type, the content of clay minerals, and the interactions between the clay mineral particles. The proportion of clay minerals, even in small quantities, can have significant effect on the engineering behavior of the soil mass [6]. A review of literature also shows that clay slopes that fail in the field experience seasonal rainfall and sunny climate conditions. The continuous exposure to wetting-drying cycles can reduce the overall mechanical strength [7-10]. This phenomenon is typically known to cause deformation and failure of engineering structures. In view of all that has been studied so far, one may suppose that the proportion of expansive clay minerals coupled with exposure to cyclical dry and wet environments are the two key factors that control the behavior of expansive clays. Nonetheless, the evidence of the relationship between these two key factors and shear strength reduction in clay soils is inconclusive. Wright et al. [11] attempted to demonstrate that cyclic wetting and drying can loosen the soil structure and reduce the strength of compacted clays towards the fully softened strength. Their work, however, focused on natural soils from Texas and therefore the extent to which their conclusions and assumptions can be applied is limited to soils with similar properties. To date, a great deal of research into clays has focused on the swelling and shrinkage characteristics [12-16]; however, the contribution of clay mineral content to the 
essential mechanism of strength reduction has not been well understood.

This paper describes an experimental investigation of the shear strength behavior of different compacted artificial soil mixes with different clay mineral contents. By choosing to use artificial soil mixes, the spatial variability that occurs in natural high plastic clay soils is decreased to the barest minimum, and the influence of the dominant clay minerals can be adequately studied.

\section{Materials and Methods}

2.1. Soils. In this study, 11 different remolded samples were prepared by combining double mixtures of commercially available powdered kaolinite, montmorillonite, and quartz in proportions of $30 \%, 50 \%, 70 \%$, and $100 \%$ based on dry weight. To ensure that clay soils of varying strength characteristics were obtained for this study, kaolinite which is the strongest clay mineral and montmorillonite which is the weakest were chosen. Henceforth, the letters K, M, and Q in the sample description represent kaolin, montmorillonite, and quartz, respectively, whilst the proceeding numbers denote the percentage of those minerals in the mixture. The physical and plasticity properties of the soils used were investigated in accordance with the procedures specified by the Chinese standard GB/T 50123-1999 (Ministry of Construction P. R China, 1999). The montmorillonite had a liquid limit of 328 , a plastic limit of 33 , a specific gravity of 2.69, and 90\% clay-sized particles (particles smaller than $0.005 \mathrm{~mm}$ ). The pure kaolin on the other hand was characterized by a specific gravity of 2.60 , a liquid limit of 55 , and a plastic limit of 27 . About $90 \%$ of the kaolin contained claysized particles. The quartz had a specific gravity of 2.65 , and approximately, $70 \%$ of the quartz fell within the silt range $(0.005 \mathrm{~mm}$ and $0.075 \mathrm{~mm})$. Figure 1 shows the particle size distribution curves for various minerals obtained using a BT9300H laser particle size analyzer. Also, the X-ray diffraction test was conducted on the kaolin and montmorillonite samples that were purchased to identify their clay mineral compositions. The samples were dried and placed in a Rigaku DMAX/RB instrument with $\mathrm{Cu} \mathrm{Ka}$ radiation. The major crystalline phases were investigated at an angular range of $5-90^{\circ}(2 \theta)$ with an increment of $0.02^{\circ}$ per step. The diffraction pattern and peaks were compared with standard patterns prepared by the Committee of Powder Diffraction Data Service using Jade software. The result is presented in Figure 2.

2.2. Preparation of Samples. Compaction test was performed in accordance with the Chinese standard GB/T 50123 [17] for the proctor compaction test. $2.3 \mathrm{~kg}$ of each soil mixture with the designated mineral composition by weight was measured and mixed in the dry state until a fairly uniform distribution was obtained. A $102 \mathrm{~mm}$ diameter mold was used to compact the samples by dropping a $5.5 \mathrm{lbf}(24.4 \mathrm{~N})$ rammer from a height of $305 \mathrm{~mm}$ into three layers with 25 blows each. For each soil mixture, a minimum of 5 samples at different moisture contents were prepared. Following the

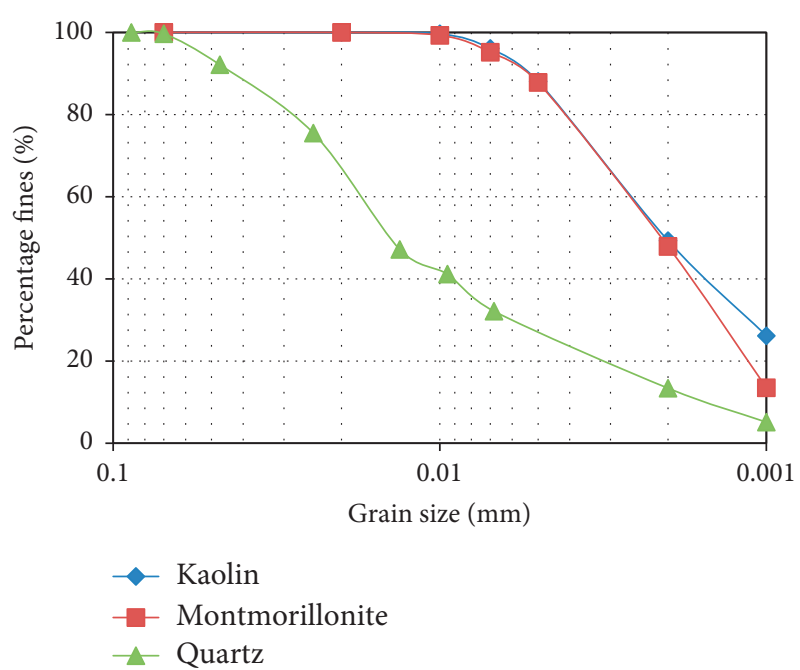

FIGURE 1: Grain size distribution of kaolin, montmorillonite, and quartz.

determination of the maximum dry density and optimum moisture content of each soil sample, it was necessary to replicate the soil conditions for the direct shearing test. Therefore, all the soil mixtures in their appropriate mineral proportions were statically compacted into steel rings with a diameter of $61.8 \mathrm{~mm}$ and a height of $20 \mathrm{~mm}$ at optimum conditions. A hydraulic jack was used to compact the samples. The inside of the rings was lubricated to reduce friction between the samples and the steel rings.

2.3. Wetting and Drying Cycles. The statically compacted remolded samples in the steel rings were subjected to continuous wetting and drying to simulate the effect of rainfall and drought on compacted clay soils. Each sample was sandwiched between a filter paper and a porous stone to allow for double drainage. A steel ring together with porous stones and an elastic rubber membrane were used to secure the sample from disintegrating.

All specimens were subjected to 15 cycles of wetting and drying. This was enough to ensure maximum expansion of the clay soils and no further noticeable particle breakdown. The first cycle consisted of a wetting phase followed by a drying phase and another wetting phase. For each wetting cycle, the samples were inundated in water for a period of 24 hours whilst for the drying phase, each sample was kept in the oven at a temperature of $40 \pm 5^{\circ} \mathrm{C}$ until the moisture content dropped to about $50 \%$ less than the compacted moisture content. This was checked by taking the samples out of the oven periodically and measuring the weight.

2.3.1. Direct Shear Test. The test was conducted in accordance to the procedures outlined in the Chinese standard GB/T 50123 [17] for determining the shear strength of the soil using a shear box. Two series of unconsolidated quick direct shear tests were performed on the soil mixtures. In the first series (as-compacted samples), the specimen was compacted and subjected to the direct shear test immediately 


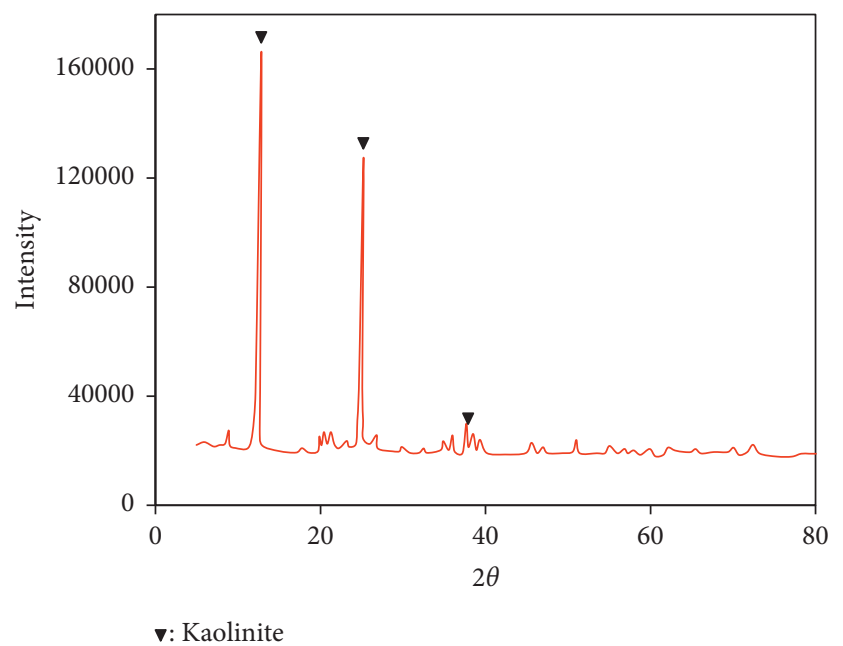

(a)

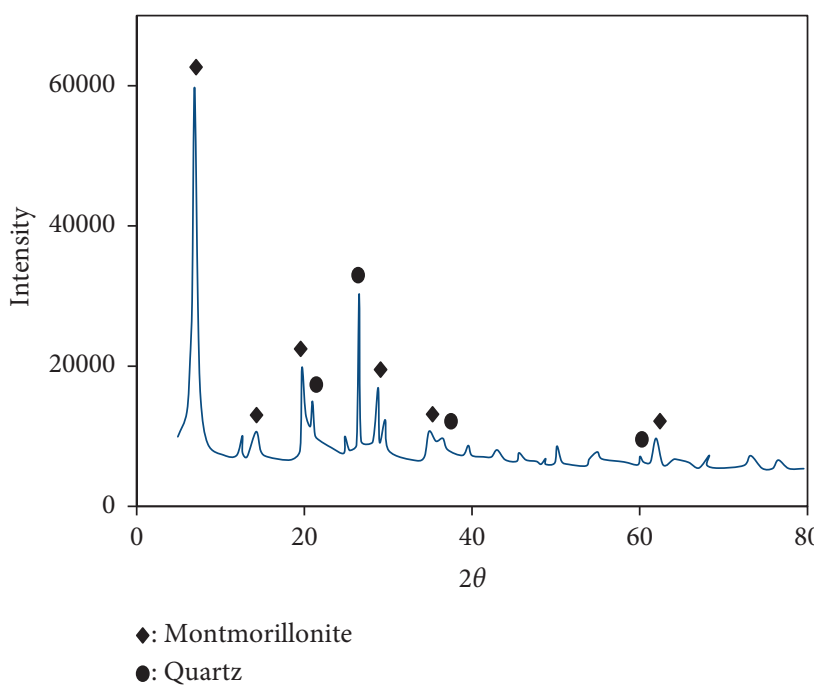

(b)

FIGURE 2: XRD analysis of (a) kaolin and (b) montmorillonite.

afterwards. In the second series, the specimen was compacted and then exposed to wetting and drying cycles before it was sheared. The shear strength parameters investigated were cohesion and internal angle of friction. Four direct shear tests were conducted on each soil mixture using vertical stresses of $50 \mathrm{kPa}, 100 \mathrm{kPa}, 150 \mathrm{kPa}$, and $200 \mathrm{kPa}$. A strain rate of $0.08 \mathrm{~mm} / \mathrm{min}$ was applied in all the tests.

\section{Results and Discussion}

3.1. Shear Strength Parameters of As-Compacted Samples. To evaluate the cohesion and frictional strength behavior under peak conditions, the Mohr-Coulomb failure criterion was used to analyze each measured dataset. The plot of peak shear stress for different proportions of the kaolin-quartz mixture is depicted in Figures 3(a) and 3(b). The data for pure end sample of kaolin were added for reference. It was observed that increasing the proportion of kaolin led to an increase in cohesion and a decrease in the internal friction angle. The cohesion increased from $67.7 \mathrm{kPa}$ for K30Q70 to $97.7 \mathrm{kPa}$ for K70Q30 whiles the angle of internal friction decreased from $30.4^{\circ}$ to $18.9^{\circ}$, respectively. Further increase in the kaolin content from K70Q30 to K100 resulted in a continuous decrease in the friction angle as shown in Figure 3(b) and a slight decrease in cohesion, as shown in Figure 3(a).

From Figure 3(a), the initial increase in cohesion may be attributed to decrease in the void ratio with increase in the kaolin content. The kaolin particles to some extent behaved as a filling material in the pore spaces of the relatively larger and dense quartz (up to $70 \%$ ). However, beyond $70 \%$ kaolin content (when the void ratio reached a minimum), the quartz particles became more dispersed and more water was needed to reach maximum cohesion. It can be concluded that this decreased the electromagnetic attractions between the kaolin clay particles and caused the cohesion to decrease slightly. The trend is similar to the results presented by
Mullins and Panayiotopoulos [18]. The plausible explanation for the results in Figure 3(b) is that as the kaolin content increased, the clay particles controlled the overall behavior of the mixture causing the quartz particles to slip and slide, leading to a reduction in the frictional strength. The trend is qualitatively similar to those presented by Lupini et al. [19].

Figure 4 shows shear strength data for montmorillonitequartz mixtures. The cohesion behavior was more dominant but similar to the trend observed in the kaolin-quartz mixtures. From Figure 4(a), it can be observed that increasing the montmorillonite content from M30Q70 to M70Q30 led to an increase in the cohesion shear strength. Interestingly, the pure end data of the M100 sample also exhibited a slight decrease in cohesion. Figure 4(b) shows how the friction angle changes with increasing montmorillonite content. The relationship observed in Figure 4(b) shows a disjointed pattern. The pattern shows a moderate drop in friction up to $50 \%$. From $50 \%$ to $70 \%$, the friction angle increased steeply with increasing montmorillonite content. From M70Q30 to M100, another decrease in the friction angle was observed similar to the initial trend.

Using the montmorillonite X-ray diffraction analysis presented in Figure 2, an attempt was made to explain the result in Figure 4. Figure 2(b) shows that the montmorillonite mineral contains about $10-15 \%$ quartz. It was deduced that as the proportion of montmorillonite was increased from $30 \%$ to $50 \%$, the friction angle reduced because of increasing clay content and decreasing quartz content. However, just after $50 \%$, the extra contribution of quartz from the montmorillonite specimen led to the discrepancy in the trend. As such, the sudden increase in frictional strength may be as a result of the relatively high proportion of quartz in the mixture. Coincidentally, increasing quartz particles increased the frictional angle. Beyond 70\% montmorillonite content, it can be assumed that the clay particles were dominant and caused the frictional strength to decrease again. 


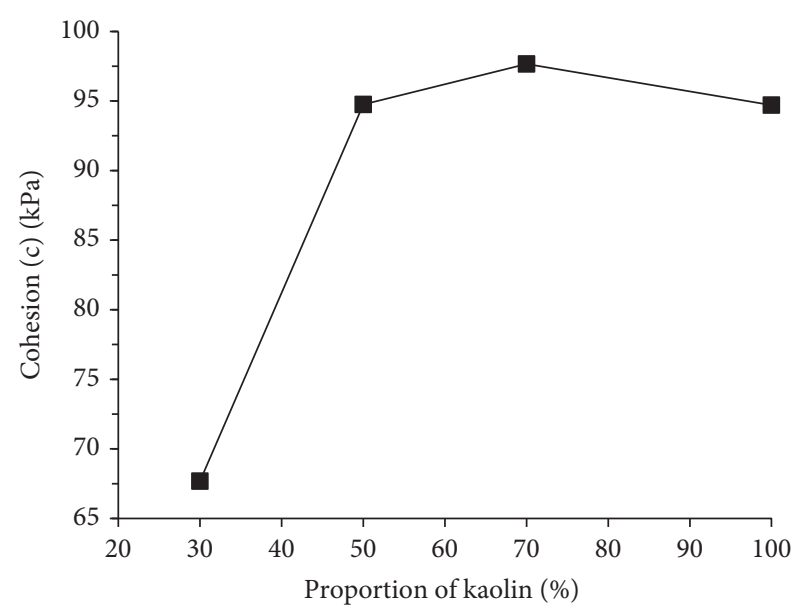

(a)

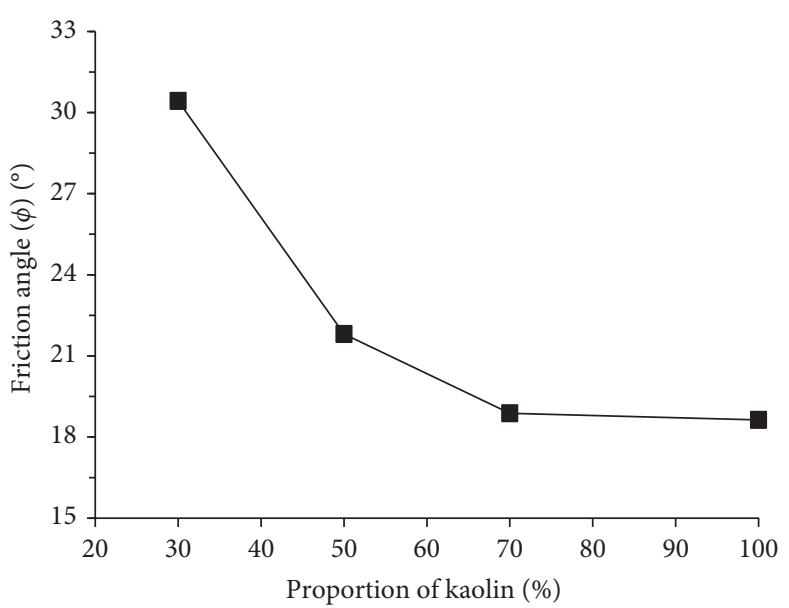

(b)

FIGURE 3: Variation of shear strength properties with clay proportion in the kaolin-quartz mixture: (a) cohesion and (b) frictional angle.

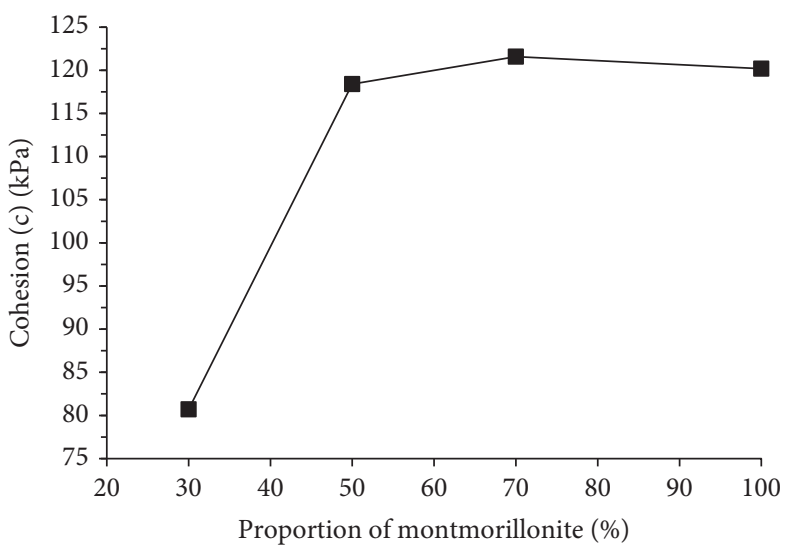

(a)

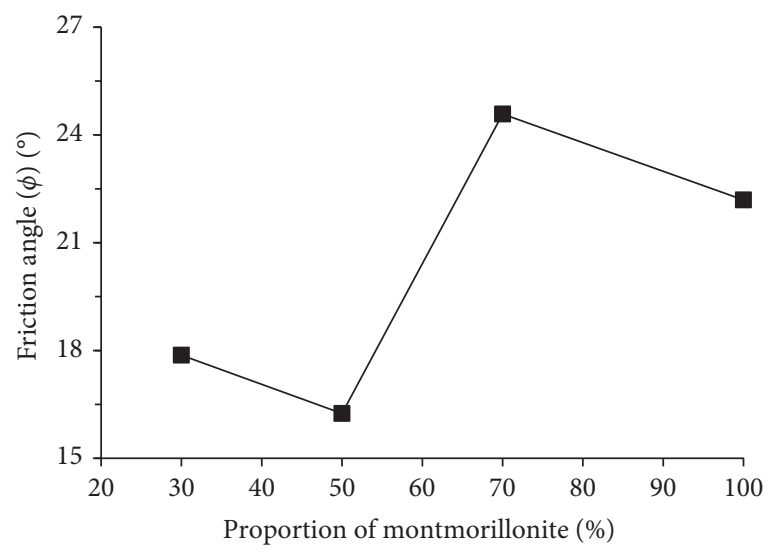

(b)

Figure 4: Variation of shear strength properties with clay proportion in the montmorillonite-quartz mixture: (a) cohesion and (b) frictional angle.

The data for montmorillonite-kaolin mixtures (30\%, 50\%, and $70 \%$ ) are plotted in Figure 5. It can be seen in Figure 5(a) that cohesion decreased from $88.9 \mathrm{kPa}$ to $74.9 \mathrm{kPa}$ when the content of montmorillonite was increased from $30 \%$ to $70 \%$. This observation confirms the trend of results shown in Figures 3 and 4 . As the mixture of montmorillonite and kaolin can basically be considered to be pure clay, it seems to be the point that when the content of kaolin and montmorillonite content were increased from $70 \%$ to $100 \%$ in the kaolinquartz mixture and montmorillonite-quartz mixtures, respectively, the behavior of these mixtures gradually approached that of a pure clay soil. So the influence of the quartz in Figures 3 and 4 was suppressed in the mixtures at this point. When the mixtures approached pure clay soils, increasing the clay content beyond a certain critical moisture content caused the cohesion to decrease. The variation of the friction angle with increasing proportion of montmorillonite as presented in Figure 5(b) shows an increase in frictional strength with increasing montmorillonite content. The X-ray diffraction results for pure kaolin (see Figure 2(a)) show that the kaolin used was about $98 \%$ pure and therefore any behavior observed is mostly due to kaolin clay particles. However, the montmorillonite had a few quartz particles as earlier on explained. So with increasing proportion of montmorillonite in this mixture, the cohesion decreased due to the increased presence of quartz particles. The frictional strength on the other hand increased because the increased quartz particles from the montmorillonite specimen possess high frictional strength.

3.2. Effects of Optimum Moisture Content on the Shear Strength of As-Compacted Samples. To examine why the difference in cohesion and friction angle was observed in the various mixtures in Figures 3-5, the cohesion and friction angles were analyzed in relation to the moisture content at which samples were compacted for kaolin-quartz mixtures, montmorillonite-quartz mixtures, and montmorillonitekaolin mixtures, as shown in Table 1 . It was observed that initially as the water content increased from about $17.4 \%$ to $28.8 \%$, all samples which were compacted in that range 


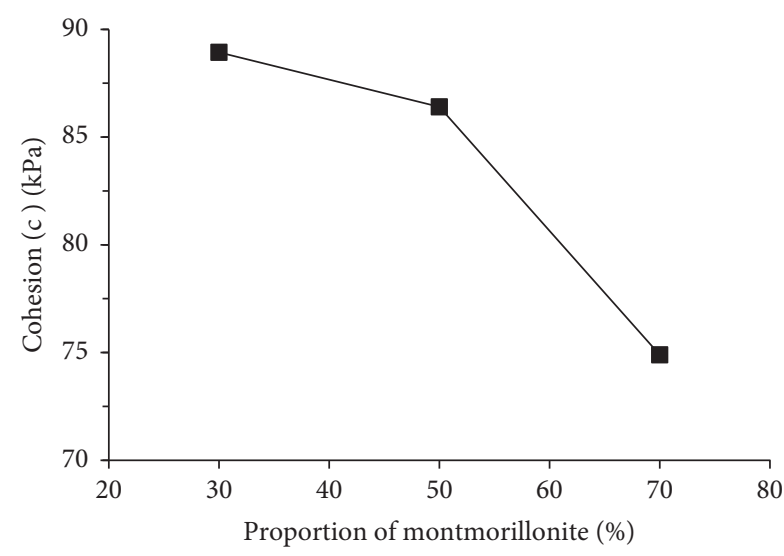

(a)

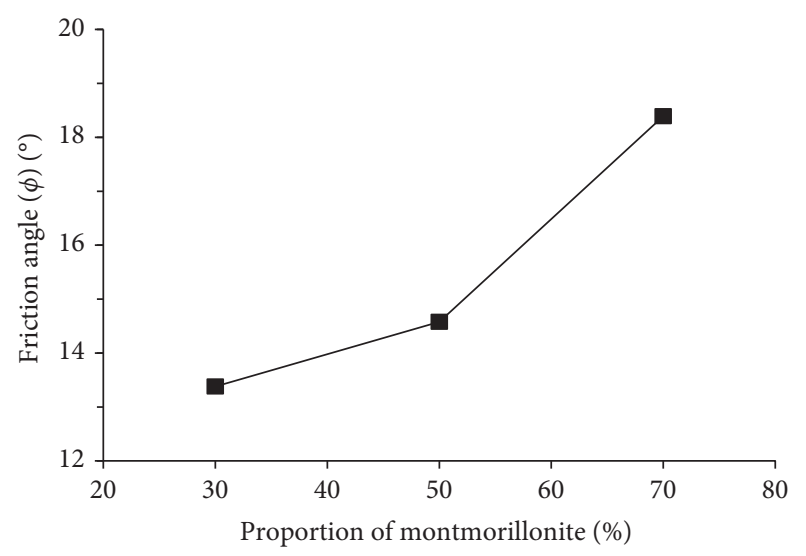

(b)

FIGURE 5: Variation of shear strength with clay proportion in the montmorillonite-kaolin mixture: (a) cohesion and (b) frictional angle.

TABLE 1: Shear strength results with water content for as-compacted soils.

\begin{tabular}{lccc}
\hline Samples & Cohesion $(\mathrm{c}), \mathrm{kPa}$ & Frictional angle $(\varphi)$, degree & Water content $(\%)$ \\
\hline K30Q70 & 67.68 & 30.43 & 17.4 \\
K50Q50 & 94.75 & 21.81 & 21.3 \\
K70Q30 & 97.66 & 18.88 & 26.1 \\
K100 & 94.70 & 18.63 & 32.6 \\
M30Q70 & 80.71 & 17.87 & 22.1 \\
M50Q50 & 118.40 & 16.25 & 24.1 \\
M70Q30 & 121.57 & 24.58 & 28.8 \\
M100 & 120.18 & 22.19 & 38.3 \\
M30K70 & 88.93 & 13.38 & 34.5 \\
M50K50 & 86.40 & 14.58 & 35.8 \\
M70K30 & 74.89 & 18.39 & 40.3 \\
\hline
\end{tabular}

exhibited a trend of increasing cohesion with increasing water content. However, beyond that range, any other specimen that was prepared in all the three mixture groups exhibited a decreasing cohesion pattern with increasing water content. Therefore, the decrease in cohesion between $75 \%$ and $100 \%$ montmorillonite content in the montmorillonite-quartz mixture and kaolin in the kaolin-quartz mixture as well as the continuous decrease in cohesion observed in the montmorillonite-kaolin mixture with increase in the montmorillonite content, respectively, can be partly attributed to the high water content at which they were compacted. In general, it can be explained that as the water content was increased beyond the critical maximum value, the distance of separation between the clay minerals increased and the electrostatic attractions (van der Waals forces) decreased. The influence of water content can also be explained by the orientation of clay particles compacted at wet and dry side of optimum [20]. Al-Shayea [21] studied the influence of the clay and moisture content on remolded unsaturated soils using the Mohr-Coulomb shear criterion. His results showed that cohesion increases to a maximum and then declines for all clay contents similar to the shape of a compaction curve. He explained that this behavior is attributed to cementation and adhesion due to compaction, electrostatic and electromagnetic attractions, and capillary suction. He further observed that all these sources of cohesion increase the cohesion intercept with increasing clay content and increasing water content. However, the effect of increasing water content was only to certain maximum limits, beyond which it begins to decrease.

3.3. Shear Strength Parameters of the Specimen Subjected to Wetting and Drying. Seasonal climatic variation in clay soils induces shrinkage and swelling leading to changes in soil behavior and posing difficulties in engineering field application [22]. Figure 6 presents the plots of cohesion and friction angles versus the proportion of different clay minerals to show the effect of cyclic wetting and drying on the shear strength characteristics of compacted soils after being subjected to 15 cycles of wetting and drying.

3.3.1. Influence of Wet and Dry Cycles on Cohesion. Generally it can be seen in Figure 6 that when specimens were subjected to continuous wetting and drying, the cohesive strength of the soils was dramatically reduced in all clay mixtures. In the kaolin-quartz mixture, as shown in Figure 6(a), the K30Q70 exhibits complete drop in cohesion after 15 cycles of wetting and drying. The lowest percentage reduction in cohesion was recorded in K50Q50 with a value of $89 \%$. Similar reduction in cohesive strength was observed in montmorillonite-quartz as depicted in Figure 6(c) and 


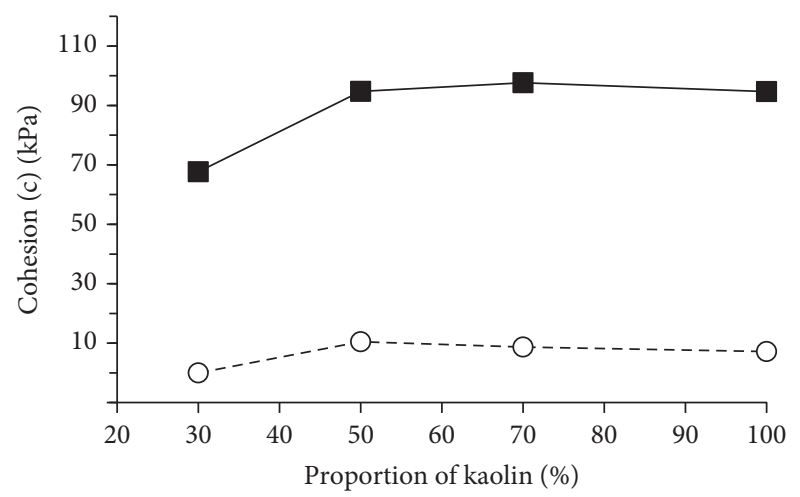

As compacted -O- After wet and dry cycles

(a)

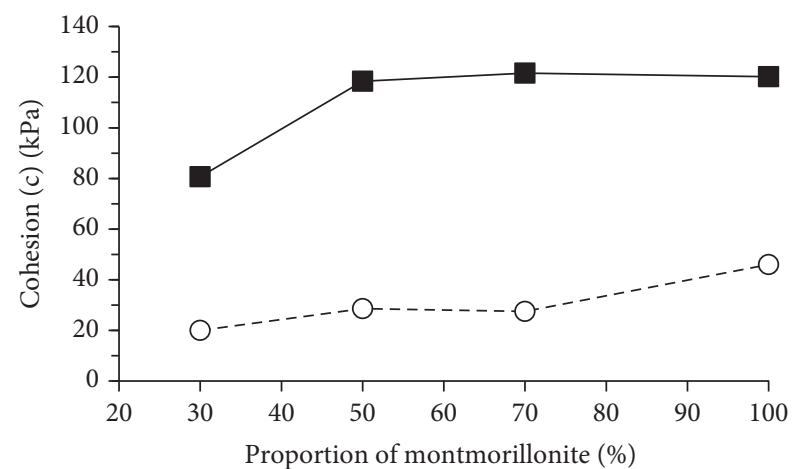

As compacted

- - After wet and dry cycles

(c)

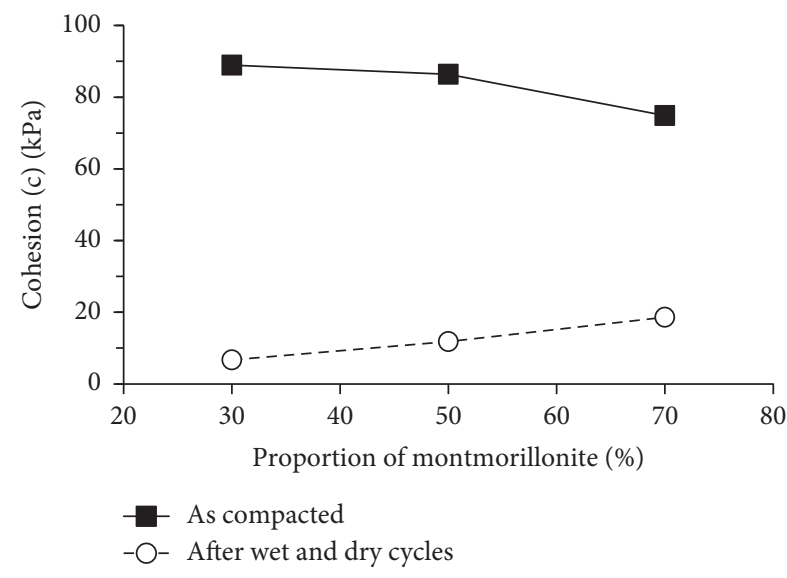

(e)

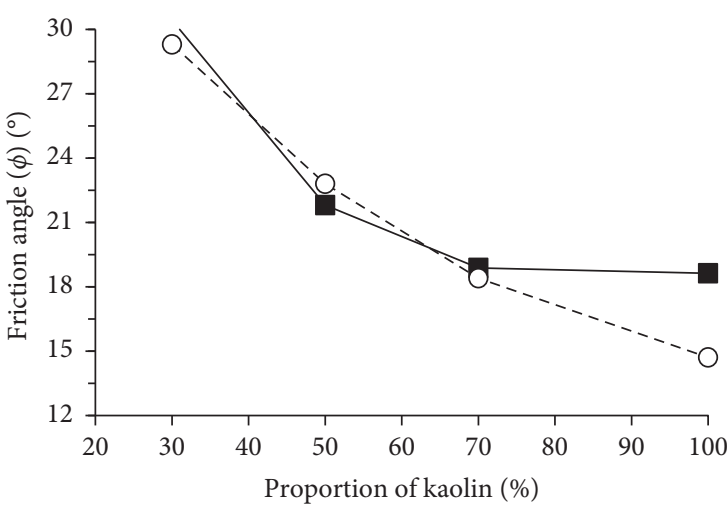

As compacted

-O- After wet and dry cycles

(b)

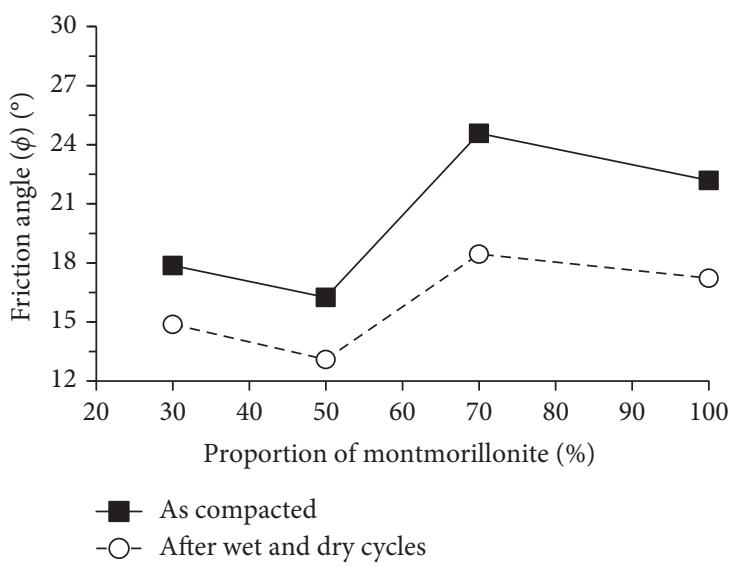

(d)

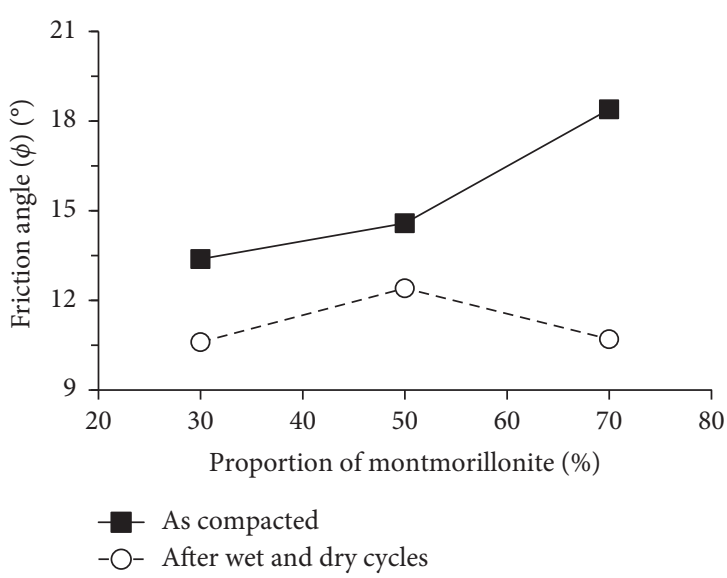

(f)

FIGURE 6: Comparison of shear strength characteristics between the as-compacted specimen and specimen subjected to wetting and drying: (a, b) kaolin-quartz mixtures; (c, d) montmorillonite-quartz; (e, f) montmorillonite-kaolin mixture.

montmorillonite-kaolin mixtures, as shown in Figure 6(e). Generally, the reduction in cohesion in both montmorillonite-quartz mixtures and kaolin-quartz mixtures was very high. The pure montmorillonite specimen recorded a lower value of $62 \%$ reduction. Also, the montmorillonite-kaolin samples recorded significant reduction in cohesion with a minimum of $75 \%$ in $\mathrm{M} 70 \mathrm{~K} 30$.
3.3.2. Influence of Wet and Dry Cycles on Friction. Figure 6 also shows the effect of wetting and drying on the friction angle of the compacted clay specimens. It can be seen that the difference in the friction angle between the ascompacted specimen and the wet and dry specimen is not very significant after 15 cycles of wetting and drying. It is noticeable that the K30Q70, K70Q30, and K100 specimens 
exhibited slight reductions in frictional strength. However, $\mathrm{K} 50 \mathrm{Q} 50$ showed a deviation from this trend as there is about $5 \%$ increase in friction. In the montmorillonite-quartz group from Figure 6(d), it can be observed that frequent wetting and drying caused relatively greater decrease in the friction angle. The plot for montmorillonite-kaolin mixtures presented in Figure 6(f) also shows results similar to the montmorillonite-quartz mixtures. Generally, it can be noticed that increased kaolin and montmorillonite content in both kaolin-dominated soils and montmorillonite-dominated soils led to a relatively smaller decrease in the friction angle after 15 cycles. Rogers and Wright [23] after carrying out repeated wetting and drying on packed remolded clays also noticed that there was no significant change in the friction angles that was observed.

\section{Conclusions}

Based on laboratory testing of 11 artificial clay soil mixtures consisting of kaolinite, montmorillonite, and quartz, the shear strength characteristics of compacted clays before and after subjecting to cyclic wetting and drying conditions were analyzed. The impact of dominating clay mineral and cyclic wetting and drying on the cohesion and frictional strength behavior were described, and the following conclusions can be drawn:

(1) For the as-compacted samples, the frictional and cohesion shear strength appeared to be affected by the clay mineral content. The cohesion increases with increase in the kaolin/montmorillonite content up to a maximum of about $70 \%$ clay content. Afterwards, no appreciable change was observed as the cohesion only decreased moderately with further increase in kaolin/montmorillonite. The increase in cohesion was partly attributed to decrease in the void ratio with increase in the clay content.

(2) At the same clay mineral content, montmorillonitedominated mixtures achieved a high cohesion shear than kaolin-dominated mixtures in the as-compacted samples. The quantity and type of clay minerals are thus important when determining the shear strength.

(3) Generally, when specimens were subjected to continuous wetting and drying, the cohesive strength of the soils were dramatically reduced in all clay mixtures. The reduction in cohesion in the montmorillonite-quartz mixtures was relatively smaller compared to that in the kaolin-quartz mixtures.

By eliminating external factors involved in natural soil formation, this study has demonstrated that the content of clay minerals is a major factor for shear strength reduction and may be the cause of sudden failures in clay slopes.

\section{Data Availability}

The data used to support the findings of this study are included within the article.

\section{Conflicts of Interest}

The authors declare that they have no conflicts of interest.

\section{Acknowledgments}

The authors appreciate the financial support provided by the National Science Foundation of China (no. 51578214 and no. 41530637).

\section{References}

[1] A. W. Skempton, "Long-term stability of clay slopes," Géotechnique, vol. 14, no. 2, pp. 77-102, 1964.

[2] A. W. Skempton, "Residual strength of clays in landslides, folded strata and the laboratory," Géotechnique, vol. 35, no. 1, pp. 3-18, 1985.

[3] G. H. Gregory and A. Baryun, "Correlation of fully-softened shear strength of clay soil with index properties," Oklahoma Department of Transportation, Planning Research Division, Oklahoma City, OK, USA, Phase I. No. FHWA-OK-10-04, 2010.

[4] G. B. Sowers and G. F. Sowers, Introductory Soil Mechanics and Foundations, p. 556, The Macmillan Company, New York, NY, USA, 1970.

[5] D. M. Potts, G. T. Dounias, and P. R. Vaughan, "Finite element analysis of progressive failure of Carsington embankment," Géotechnique, vol. 40, no. 1, pp. 79-101, 1990.

[6] R. D. Holtz and W. D. Kovacs, An Introduction to Geotechnical Engineering, Pearson, London, UK, 1981.

[7] J. Kodikara, S. L. Barbour, and D. G. Fredlund, "Changes in clay structure and behaviour due to wetting and drying," in Proceedings of the 8th Australian-New Zealand Conference on Geomechanics, pp. 179-186, Hobart, Australia, 1999.

[8] R. W. Day, Foundation Engineering Handbook, McGraw-Hill Publishing companies, New York, NY, USA, 2006.

[9] T. M. Petry and J. C. Armstrong, "Stabilisation of expansive clay soils," Transportation Research Record, vol. 1219, pp. 103-112, 1989.

[10] P. P. Hudec, "Statistical analysis of shale durability factors," Transportation Research Record, vol. 873, pp. 28-35, 1982.

[11] S. G. Wright, J. G. Zornberg, and J. E. Aguettant, "The full softened shear strength of high plasticity clays," No. FHWA/ TX-07/0-tnqh_x2010;3, Center for Transportation Research, University of Texas at Austin, Austin TX, USA, 2007.

[12] F. H. Chen and G. S. Ma, "Swelling and shrinkage behaviour of expansive clays," in Proceedings of the 6th International Conference on Expansive Soils, vol. 1, pp. 127-129, New Delhi, India, December 1987.

[13] A. E. Dif and W. F. Bluemel, "Expansive soils under cyclic drying and wetting," Geotechnical Testing Journal, vol. 14, no. 1, pp. 96-102, 1991.

[14] A. Sridharan and M. M. Allam, "Volume change behaviour of desiccated soils," Journal of Geotechnical Engineering Division, vol. 108, no. 8, pp. 1057-1071, 1982.

[15] R. W. Day, "Swell-shrink behavior of compacted clay," Journal of Geotechnical Engineering, vol. 120, no. 3, pp. 618623, 1994.

[16] K. S. Subba Rao, S. M. Rao, and S. Gangadhara, "Swelling behaviour of a desiccated clay," Geotechnical Testing Journal, vol. 23, no. 2, pp. 193-198, 2000.

[17] Ministry of Construction, "Standard for soil test method," Tech. Rep. GB/T 50123-1999, Ministry of Construction, Beijing, China, 1999. 
[18] C. E. Mullins, "Standard for soil test method," Journal of Soil Science, vol. 35, no. 3, pp. 459-468, 1984.

[19] J. F. Lupini, A. E. Skinner, and P. R. Vaughan, "The drained residual strength of cohesive soils," Géotechnique, vol. 31, no. 2, pp. 181-213, 1981.

[20] T. W. Lambe and R. V. Whitman, Soil Mechanics, SI Version J Wiley and Sons, Toronto, Canada, 1979.

[21] N. A. Al-Shayea, "The combined effect of clay and moisture content on the behavior of remolded unsaturated soils," Engineering Geology, vol. 62, no. 4, pp. 319-342, 2001.

[22] M. M. Allam and S. Sridharan, "Effect of wetting and drying on shear strength," Journal of the Geotechnical Engineering Division, vol. 107, no. 4, pp. 421-438, 1981.

[23] L. E. Rogers and S. G. Wright, The Effects of Wetting and Drying on the Long- Term Shear Strength Parameters for Compacted Beaumont Clay, p. 146, Center for Transportation Research, University of Texas at Austin, Austin, TX, USA, 1986. 


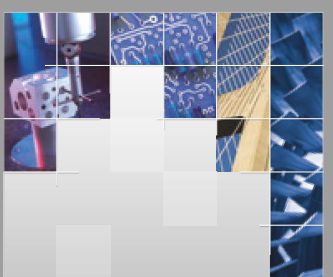

\section{Enfincering}
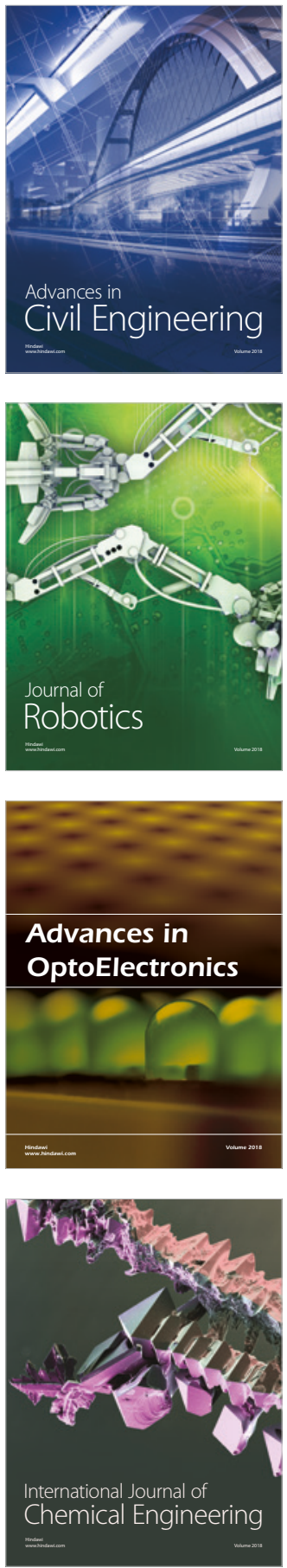

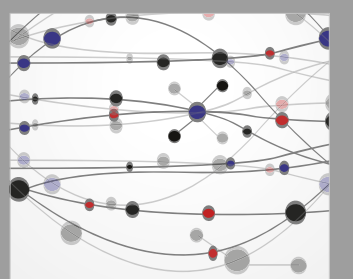

\section{Rotating \\ Machinery}

The Scientific World Journal

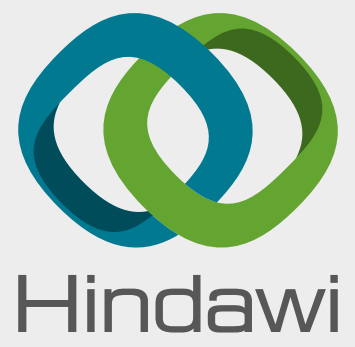

Submit your manuscripts at

www.hindawi.com
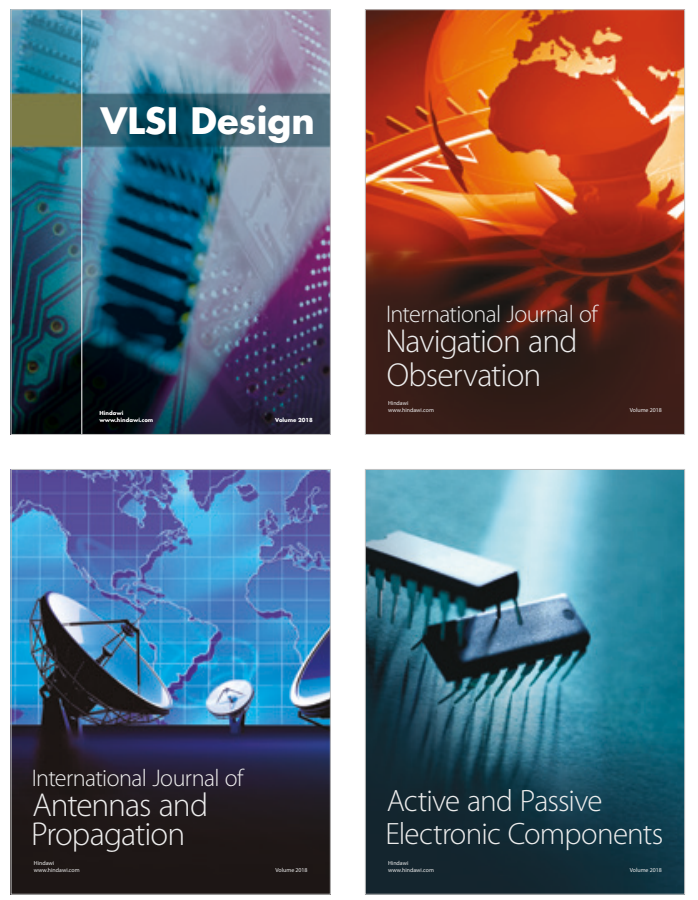
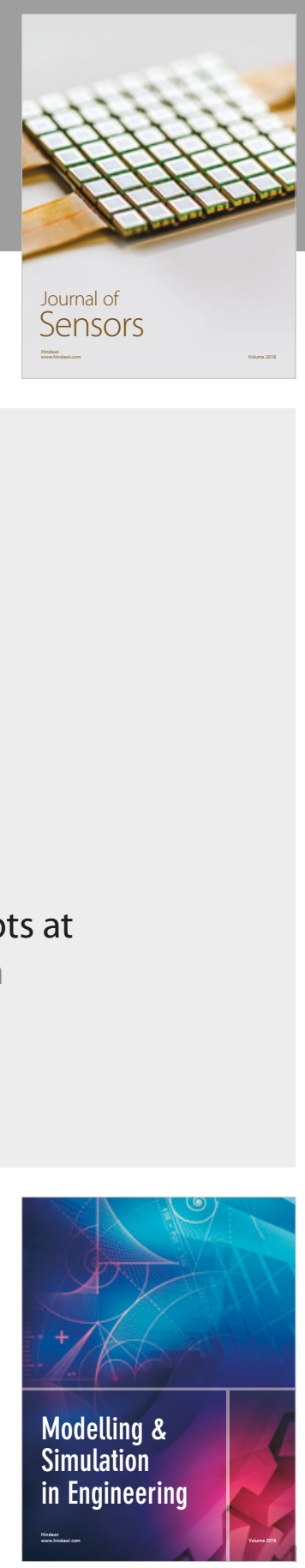

\section{Advances \\ Multimedia}
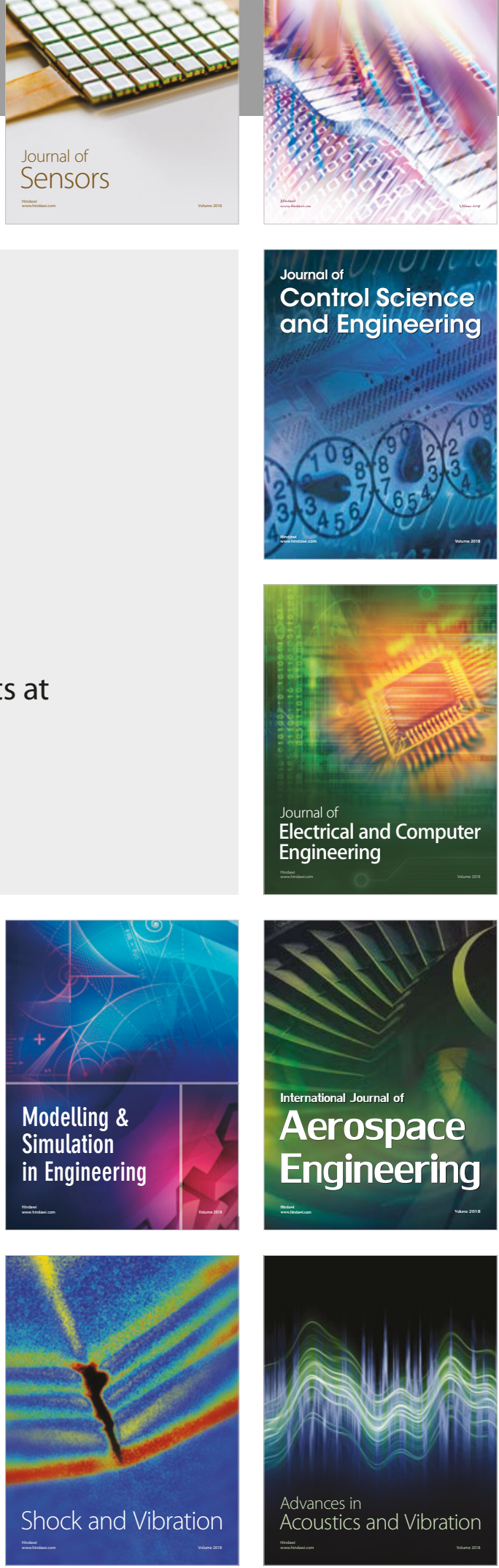